\title{
Synthesis and Characterization of the Adducts of Bis(O-ethyldithiocarbonato)copper(II) with Substituted Pyridines
}

\author{
Gurpreet Kour, Inderjeet Kour, and Renu Sachar \\ Department of Chemistry, University of Jammu, Babasaheb Ambedkar Road, Jammu Tawi, Jammu 180006, India \\ Correspondence should be addressed to Gurpreet Kour; gurpreetkour94@yahoo.com
}

Received 22 August 2013; Revised 29 October 2013; Accepted 12 November 2013

Academic Editor: Alfonso Castiñeiras

Copyright (c) 2013 Gurpreet Kour et al. This is an open access article distributed under the Creative Commons Attribution License, which permits unrestricted use, distribution, and reproduction in any medium, provided the original work is properly cited.

Monomeric five coordinated adducts of bis(O-ethyldithiocarbonato)copper(II) of general formula $\left[\mathrm{Cu}\left(\mathrm{C}_{2} \mathrm{H}_{5} \mathrm{OCS}\right)_{2}(\mathrm{~L})\right]$, $[\mathrm{L}=2-$, 3-, 4-methylpyridines and 2-, 3-, 4-ethylpyridines] have been synthesized and characterized by elemental analysis, i.r. and electronic spectroscopy, magnetic and conductivity measurements. Analytical results show that the adducts have 1:1 stoichiometry. The adducts were found to be paramagnetic and their magnetic moments at room temperature lie within the 1.81-1.94 B.M. range and this indicates the presence of one unpaired electron. All the adducts have distorted square pyramidal geometry.

\section{Introduction}

O-Alkyldithiocarbonates, popularly known as xanthates derivatives, have found a wide pra ctical application as addition to lubricating oils, antioxidants for polyolefins, and so forth. However, alkylxanthates are mainly used in flotation concentration of nonferrous metal sulfide ores. These are extensively used as pharmaceuticals, fungicides, pesticides, and quite recently in therapy for HIV infections [1-3]. Divalent transition metals xanthates are partly unsaturated and can therefore form $1: 1$ adducts with electron donors such as neutral nitrogen, oxygen, phosphorus, or sulfur donors in which the coordination geometry ranges from square pyramidal to trigonal bipyramidal [4]. Such adducts of many transition metals such as $\mathrm{Ni}, \mathrm{Zn}, \mathrm{Mn}, \mathrm{V}, \mathrm{Pt}$, and $\mathrm{Pd}$ are well studied, but little attention has been paid to the xanthates of copper owing to their instability. Here we report synthesis and investigation of the $1: 1$ adducts of some adducts of copper(II)xanthates with substituted pyridines such as 2-, 3-, 4-methylpyridines and 2-, 3-, 4-ethylpyridines.

\section{Experimental}

2.1. Preparation of Potassium Salt of O-ethyldithiocarbonate. Potassium salt of ethyl xanthate was prepared by the method reported in literature [5]. Into a $500 \mathrm{~mL}$ round bottomed flask, fitted with a reflux condenser, was placed 0.75 mole of potassium hydroxide pellets and $120 \mathrm{~g}$ of ethanol. The reaction mixture was heated under reflux for 1 hour. The mixture was then cooled and liquid from the residual solid was decanted off into another dry $500 \mathrm{~mL}$ flask. To this flask was added $45 \mathrm{~mL}$ ( 0.75 mole) of carbon disulfide slowly with constant shaking. The residual solid yellow mass was filtered (after cooling in ice) on a sintered glass funnel at the pump. It was washed with three $25 \mathrm{~mL}$ portions of ether. The resulting potassium salt of ethyl xanthate was dried in a vacuum desiccator over anhydrous calcium chloride. The yield was about $75 \mathrm{~g}$. It was then recrystallized from ether.

2.2. Preparation of Adducts of Bis(O-ethyldithiocarbonato)copper(II) with Substituted Pyridines. The yellow coloured parent compound copper(II)xanthate could not be isolated because it changed rapidly into brown coloured copper(I)xanthate. The addition complexes were prepared by the direct reaction of solution of metal salt, solution of potassium salt of ethylxanthate, and substituted pyridine. About $20 \mathrm{~mL}$ solution of cupric chloride dihydrate $(0.0025$ mole) in acetone was prepared. To this solution, a solution of potassium salt of ethyl xanthate $(0.005$ mole $)$ and substituted 


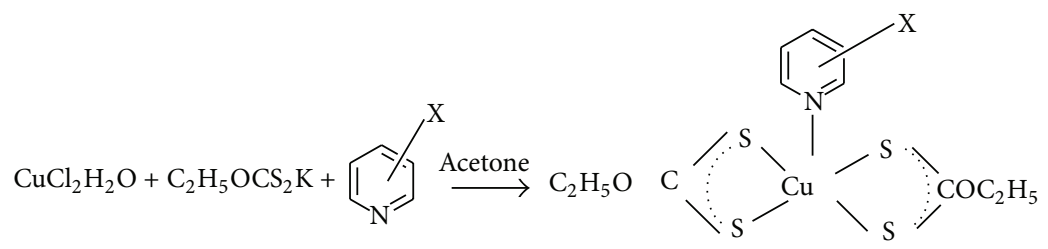

SCHEME 1: Scheme of the proposed structure, where $\mathrm{X}=\mathrm{C}_{\mathrm{C}_{2} \mathrm{H}_{5}}^{\mathrm{CH}_{3}}$.

TABLE 1: Molar conductance, magnetic moments, and analytical data of $1: 1$ adducts of bis( $O$-ethyldithiocarbonato)copper(II) with substituted pyridines.

\begin{tabular}{|c|c|c|c|c|c|c|c|c|c|c|c|}
\hline \multirow{2}{*}{ S. No. } & \multirow{2}{*}{ Name of the compound } & \multirow{2}{*}{$\begin{array}{l}\text { Molar conductance } \\
\left(\mathrm{ohm}^{-1} \mathrm{~mol}^{-1} \mathrm{~cm}^{2}\right)\end{array}$} & \multirow{2}{*}{$\begin{array}{l}\mu \text { eff (B.M.) } \\
\text { at } 293 \mathrm{~K}\end{array}$} & \multicolumn{4}{|c|}{$\%$ found } & \multicolumn{4}{|c|}{$\%$ calculated } \\
\hline & & & & $\mathrm{C}$ & $\mathrm{H}$ & $\mathrm{N}$ & S & $\mathrm{C}$ & $\mathrm{H}$ & $\mathrm{N}$ & S \\
\hline 1 & Bis(ethylxanthato)(2-methylpyridine)copper(II) & 3.49 & 1.88 & 33.0 & 3.02 & 3.0 & 32.7 & 34.4 & 3.91 & 3.64 & 33.3 \\
\hline 2 & Bis(ethylxanthato)(3-methylpyridine)copper(II) & 3.85 & 1.92 & 34.8 & 3.98 & 2.78 & 31.9 & 36.2 & 4.27 & 3.51 & 32.2 \\
\hline 3 & Bis(ethylxanthato)(4-methylpyridine)copper(II) & 4.35 & 1.93 & 35.5 & 3.55 & 2.98 & 30.8 & 36.2 & 4.27 & 3.51 & 32.2 \\
\hline 4 & Bis(ethylxanthato)(2-ethylpyridine)copper(II) & 3.89 & 1.76 & 36.6 & 4.01 & 3.15 & 30.7 & 37.9 & 4.61 & 3.40 & 31.1 \\
\hline 5 & Bis(ethylxanthato)(3-ethylpyridine)copper(II) & 3.97 & 1.82 & 36.2 & 4.00 & 3.32 & 30.6 & 37.9 & 4.61 & 3.40 & 31.1 \\
\hline 6 & Bis(ethylxanthato)(4-ethylpyridine)copper(II) & 4.74 & 1.85 & 36.6 & 3.98 & 3.20 & 30.2 & 37.9 & 4.61 & 3.40 & 31.1 \\
\hline
\end{tabular}

pyridine $(0.0025$ mole $)$ [2-methylpyridine $=0.235 \mathrm{~g}, 3$ methylpyridine $=0.235 \mathrm{~g}, 4$-methylpyridine $=0.235 \mathrm{~g}$, 2-ethylpyridine $=0.27 \mathrm{~g}$, and 3-ethylpyridine $=0.27 \mathrm{~g}$, 4-ethylpyridine $=0.27 \mathrm{~g}$ ] prepared in $50 \mathrm{~mL}$ of acetone was added slowly with constant stirring. Dark green coloured precipitates so obtained were filtered, washed with acetone, and dried over anhydrous calcium chloride in a vacuum desiccator at room temperature. A scheme of the proposed structure is shown in Scheme 1.

\section{Results and Discussion}

The addition complexes of bis(O-ethyldithiocarbonato)copper(II) are microcrystalline solids which are light green in colour. These are insoluble in common organic solvents such as ethanol, acetone, and benzene. However, these are soluble in dimethylformamide and dimethylsulfoxide. On the basis of elemental analysis (Table 1) they have been assigned the general formula $\mathrm{Cu}\left(\mathrm{S}_{2} \mathrm{COC}_{2} \mathrm{H}_{5}\right)_{2} \mathrm{~L}[\mathrm{~L}$ =2-, 3-, 4-methyl and 2-, 3-, 4-ethyl-pyridines]. Conductance values of these complexes in DMF fall in the range of 3.50$5.00 \mathrm{ohm}^{-1}$ mole $^{-1} \mathrm{~cm}^{2}$ (Table 1). These values are lower than the values expected for any uni-univalent electrolytes in this solvent suggesting that these complexes are neutral and nonionic in character $[6,7]$. The magnetic moments of $1: 1$ complexes of bis(O-ethyldithiocarbonato)copper(II) with substituted pyridines fall in the range 1.81-1.94 B.M (Table 1) which is in agreement with magnetic moment values observed for distorted square pyramidal complexes of copper(II) [8-10].

Free dithiocarbonate shows vibrations due to $\mathrm{C}-\mathrm{O}-\mathrm{C}$ stretching in the range of $1270-1280 \mathrm{~cm}^{-1}$ and the C-S stretching vibration appears as two bands in the range of $1057-1070 \mathrm{~cm}^{-1}$. In the present work, a single sharp band of high intensity has been observed in all the complexes in the range of $1011-1035 \mathrm{~cm}^{-1}$ (Table 2). The appearance of the only $\mathrm{C}-\mathrm{S}$ band suggests symmetrical bidentate binding of the dithiocarbonate moiety. There is a positive shift of 10$30 \mathrm{~cm}^{-1}$ in comparison to the free ligands. This indicates that the dithiocarbonate ligand coordinates with the metal through sulfur atoms. Moreover, the complexes show a band in the region $1190-1220 \mathrm{~cm}^{-1}$ which is attributed to $v(\mathrm{C}-\mathrm{O})$ of dithiocarbonate moiety. In these complexes $\mathrm{C}-\mathrm{H}$ out of plane bands occur at lower energy positions on complexation, indicating red shifts, which confirm that these ligands interact with the metal ion through their respective ring nitrogen atom. A new band of medium to strong intensity, observed in the range of $320-352 \mathrm{~cm}^{-1}$, may be attributed to $\mathrm{Cu}-\mathrm{S}$ stretching mode [11]. The electronic spectra of $1: 1$ addition complexes of bis( $O$-ethyldithiocarbonato)copper(II) have been recorded in DMF. The copper(II) five coordinate complexes are expected to show a strong broad band appearing in the region $12000-17500 \mathrm{~cm}^{-1}$ (Table 2). The band maximum appears around $16000 \mathrm{~cm}^{-1}$ and is assigned to $d_{x z}, d_{y z} \rightarrow$ $d_{x^{2}-y^{2}}$ transition. A weak shoulder is associated with it due to $d_{z^{2}} \rightarrow d_{x^{2}-y^{2}}$ transition. Third possible transition is orbitally forbidden and merges with the broad band. The relative energy order of these transitions depends upon the extent of axial ligand-metal interaction.

The complexes under observation show an intense band in the range of $15500-17500 \mathrm{~cm}^{-1}$ which is attributed to d$\mathrm{d}$ transitions as observed in most of the copper complexes $\left(v_{1}\right)$. This main absorption band around $16000 \mathrm{~cm}^{-1}$ can be assigned to $d_{x z}, d_{y z} \rightarrow d_{x^{2}-y^{2}}$ (Table 2). The appearance of 
TABLE 2: Electronic and vibrational spectral data of 1:1 adducts of bis(O-ethyldithiocarbonato)copper(II) with substituted pyridines.

\begin{tabular}{lcccccc}
\hline S. No. & Name of the adduct & Yield and (melting point) & $\nu_{1}\left(\mathrm{~cm}^{-1}\right)$ & $\nu(\mathrm{C}-\mathrm{S})$ & $\nu(\mathrm{C}-\mathrm{O})$ & $\nu(\mathrm{Cu}-\mathrm{S})$ \\
\hline 1 & Bis(ethylxanthato)(2-methylpyridine)copper(II) & $62 \%\left(89^{\circ} \mathrm{C}\right)$ & 16421 & 1012 & 1199 & 324 \\
2 & Bis(ethylxanthato)(3-methylpyridine)copper(II) & $68 \%\left(87^{\circ} \mathrm{C}\right)$ & 16623 & 1022 & 1210 & 335 \\
3 & Bis(ethylxanthato)(4-methylpyridine)copper(II) & $70 \%\left(88.5^{\circ} \mathrm{C}\right)$ & 16858 & 1032 & 1200 & 330 \\
4 & Bis(ethylxanthato)(2-ethylpyridine)copper(II) & $65 \%\left(86.2^{\circ} \mathrm{C}\right)$ & 16990 & 1020 & 1202 & 327 \\
5 & Bis(ethylxanthato)(3-ethylpyridine)copper(II) & $68 \%\left(86.8^{\circ} \mathrm{C}\right)$ & 16400 & 1034 & 1198 & 324 \\
6 & Bis(ethylxanthato)(4-ethylpyridine)copper(II) & $69 \%\left(87.4^{\circ} \mathrm{C}\right)$ & 15890 & 1037 & 1200 & 338 \\
\hline
\end{tabular}

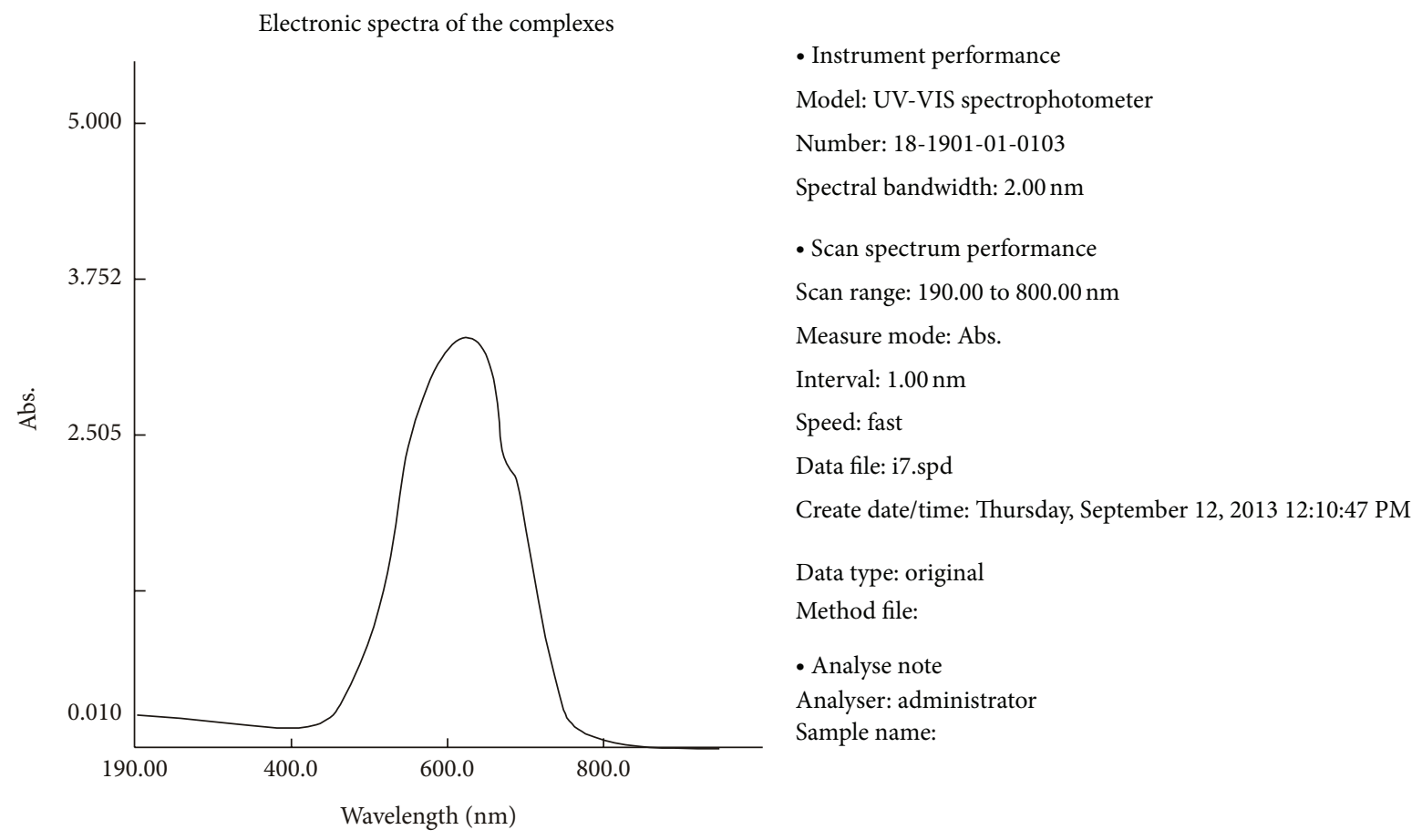

(a)

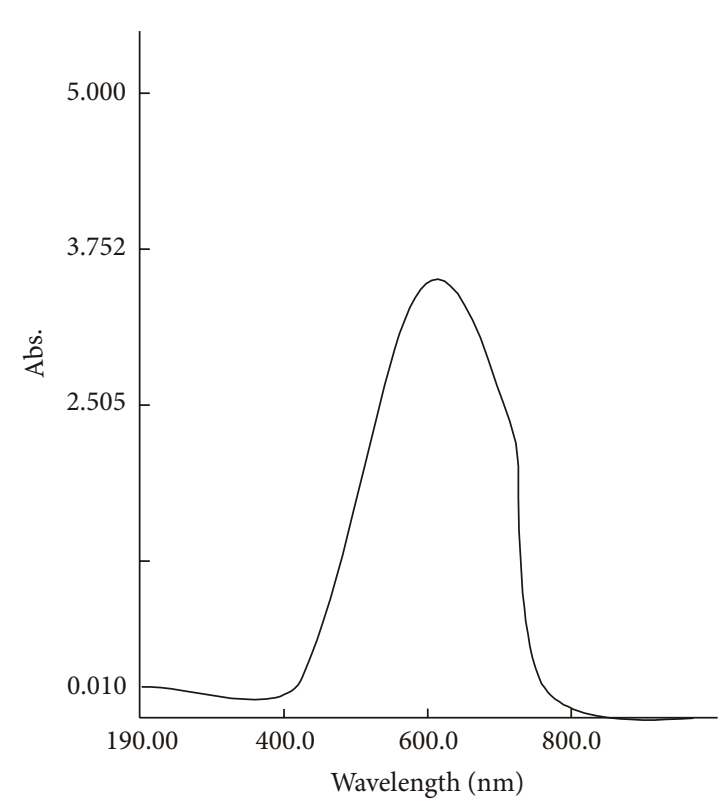

- Instrument performance

Model: UV-VIS spectrophotometer

Number: 18-1901-01-0103

Spectral bandwidth: $2.00 \mathrm{~nm}$

- Scan spectrum performance

Scan range: 190.00 to $800.00 \mathrm{~nm}$

Measure mode: Abs.

Interval: $1.00 \mathrm{~nm}$

Speed: fast

Data file: shengl.spd

Create date/time: Thursday, September 12, 2013 12:12:07:28 PM

Data type: original

Method file:

- Analyse note

Analyser: administrator

Sample name:

(b)

Figure 1 
one band with the intensity pattern suggests square pyramidal geometry around copper(II) ion in these 1:1 adducts [12] Figure 1.

\section{Conclusion}

The results obtained from various physicochemical and spectral techniques suggest that the adducts of bis(O-ethyldithiocarbonato)copper(II) with substituted pyridines have 1:1 stoichiometry with square pyramidal geometry around copper(II) ion.

\section{References}

[1] J. J. Santanaa and R. M. Souto, Honolulu PRiME the Electrochemical Society, 2012.

[2] W. Mellert, E. Amtmann, V. Erfle, and G. Sauer, "Inhibition of HIV-1 replication by an antiviral xanthate compound in vitro," AIDS Research and Human Retroviruses, vol. 4, no. 1, pp. 71-81, 1988.

[3] G. R. R. Behbehani, M. Mehreshtiagh, and L. B. A. A. Saboury, "A calorimetric investigation for the bindings of mushroom tyrosinase to p-phenylene-bis dithiocarbamate and xanthates," Journal of the Serbian Chemical Society, vol. 78, no. 2, pp. 255263, 2013.

[4] A. O. Görgülü, H. Çelikkan, and M. Arslan, "The synthesis, characterization and electrochemical behavior of transition metal complexes containing nitrogen heterocyclic sulphur donor ligandActa Chimica Slovenica," vol. 56, pp. 334-339, 2009.

[5] B. S. Furniss, A. J. Hannaford, P. W. G. Smith, and A. R. Tatchell, Vogel's Text Book of Practical Organic Chemistry, Pearson Education, London, UK, 5th edition, 1989.

[6] R. L. Martin and A. Whitley, "Magnetic studies with copper(II) salts. Part III. The constitution of copper(II)n-alkanoates in solution," Journal of the Chemical Society, vol. 13, pp. 1394-1402, 1958.

[7] W. J. Geary, "The use of conductivity measurements in organic solvents for the characterisation of coordination compounds," Coordination Chemistry Reviews, vol. 7, no. 1, pp. 81-122, 1971.

[8] R. A. Ahmadi, F. Hasanvand, G. Bruno, H. A. Rudbari, and S. Amani, "Synthesis, spectroscopy, and magnetic characterization of Copper(II) and Cobalt(II) complexes with 2-Amino-5bromopyridine as ligand," ISRN Inorganic Chemistry, vol. 2013, Article ID 426712, 7 pages, 2013.

[9] L. Singh, D. K. Sharma, U. Singh, and A. Kumar, "Synthesis and spectral studies of $\mathrm{Cu}(\mathrm{II})$ coordination compounds of $4[\mathrm{~N}$-(cinnamalidene) amino] antipyrine semicarbazone," Asian Journal of Chemistry, vol. 16, no. 2, pp. 577-580, 2004.

[10] N. H. Al-Shaalan, "Synthesis, characterization and biological activities of $\mathrm{Cu}(\mathrm{II}), \mathrm{Co}(\mathrm{II}), \mathrm{Mn}(\mathrm{II}), \mathrm{Fe}(\mathrm{II})$, and $\mathrm{UO} 2(\mathrm{VI})$ complexes with a new Schiff base hydrazone: O-hydroxyacetophenone-7-chloro-4-quinoline hydrazone," Molecules, vol. 16, no. 10, pp. 8629-8645, 2011.

[11] N. Singh and A. Parsad, "Synthesis, characterization and electrical conductivities of mixed-ligand (N, S/Se) heterobimetallic coordination polymers and their $\mathrm{I}_{2}$-doped products," Indian Journal of Chemistry A, vol. 47, pp. 650-656, 2008.

[12] M. Zhou, L. Sonq, and K. Shu, "A square-pyramidal copper(II) complex with strong intramolecular hydrogen bonds:
$\operatorname{diaqua}\left(N, N^{\prime}\right.$-dimethylformamide- $\left.\kappa \mathrm{O}\right)$ bis[2-(diphenylphosphoryl)benzoato- $\kappa \mathrm{O}]$ copper(II)," Acta Crystallographica $C$, vol. 69, pp. 463-466, 2013. 

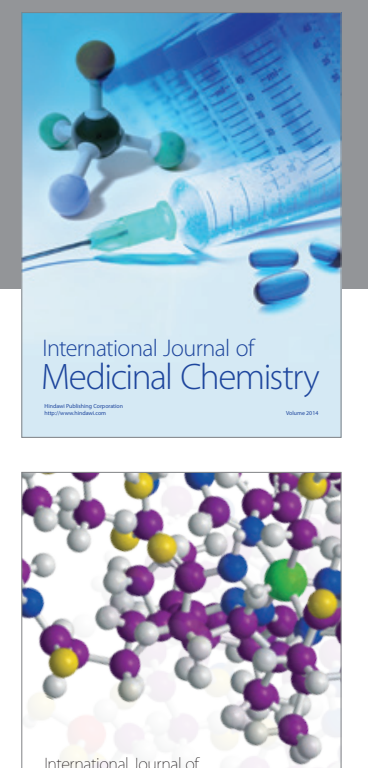

\section{Carbohydrate} Chemistry

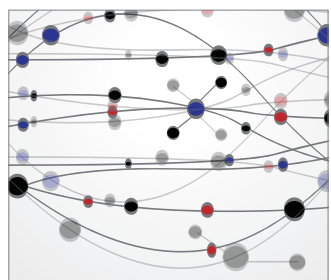

The Scientific World Journal
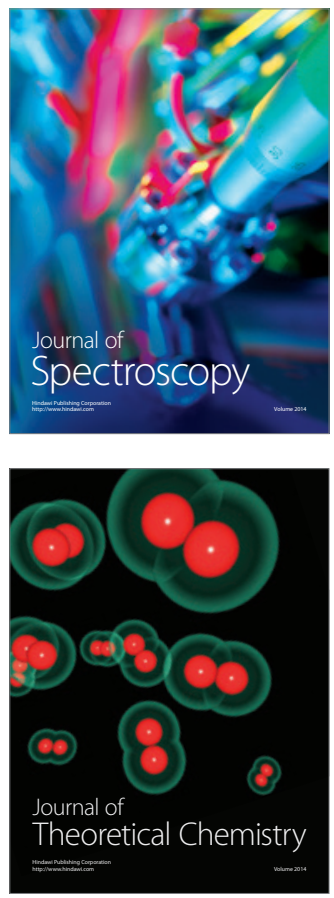
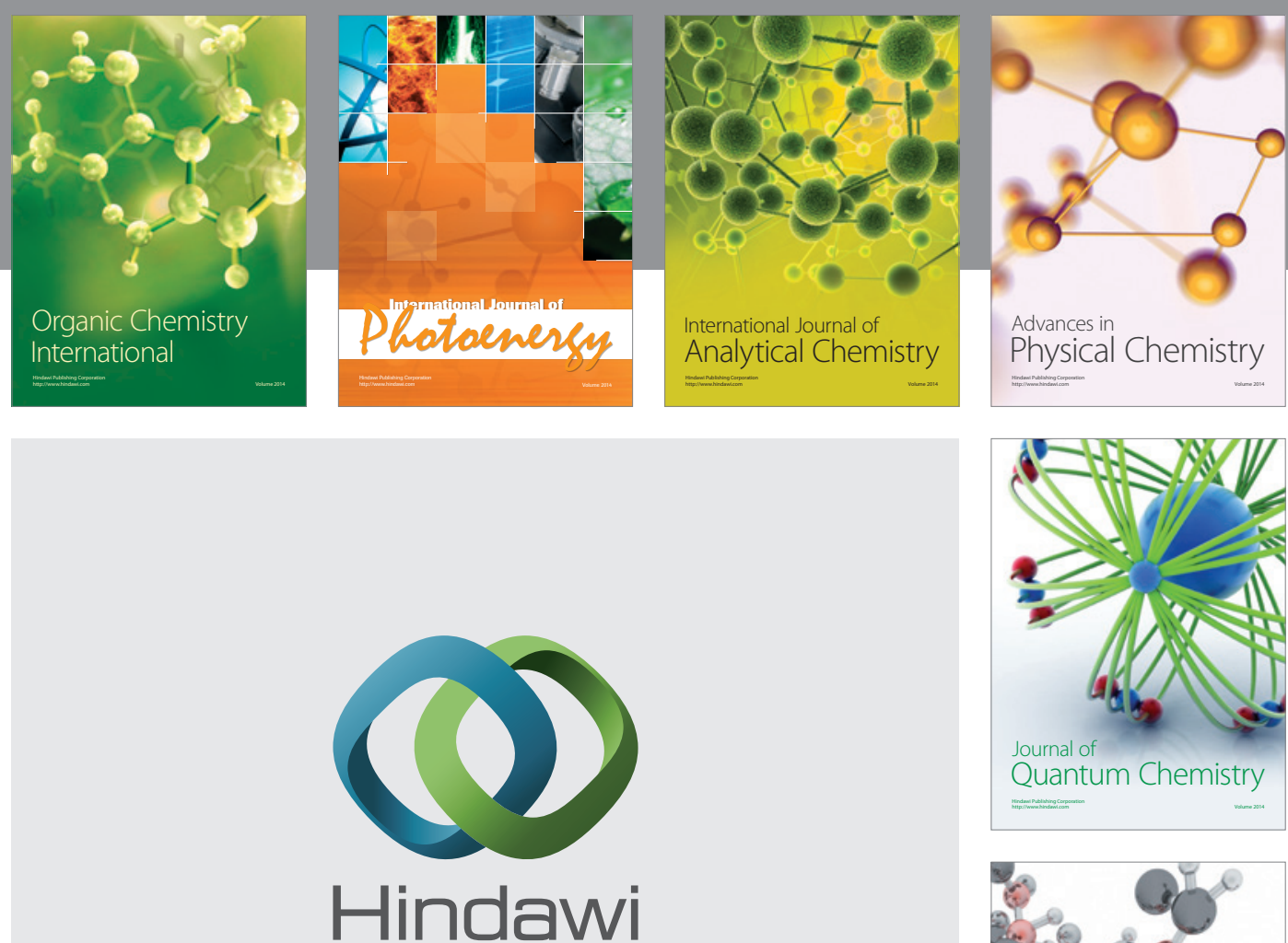

Submit your manuscripts at

http://www.hindawi.com

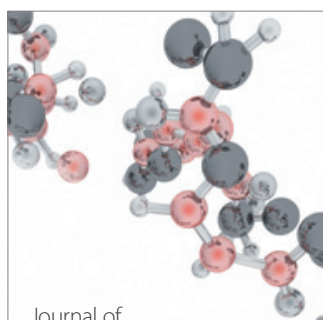

Analytical Methods

in Chemistry

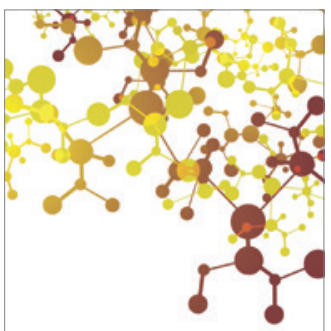

Journal of

Applied Chemistry

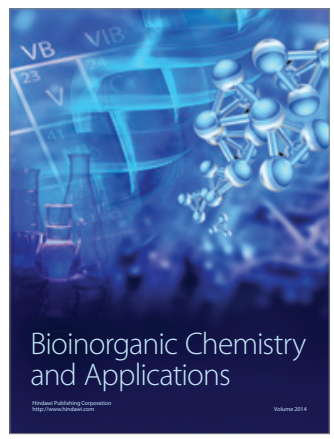

Inorganic Chemistry
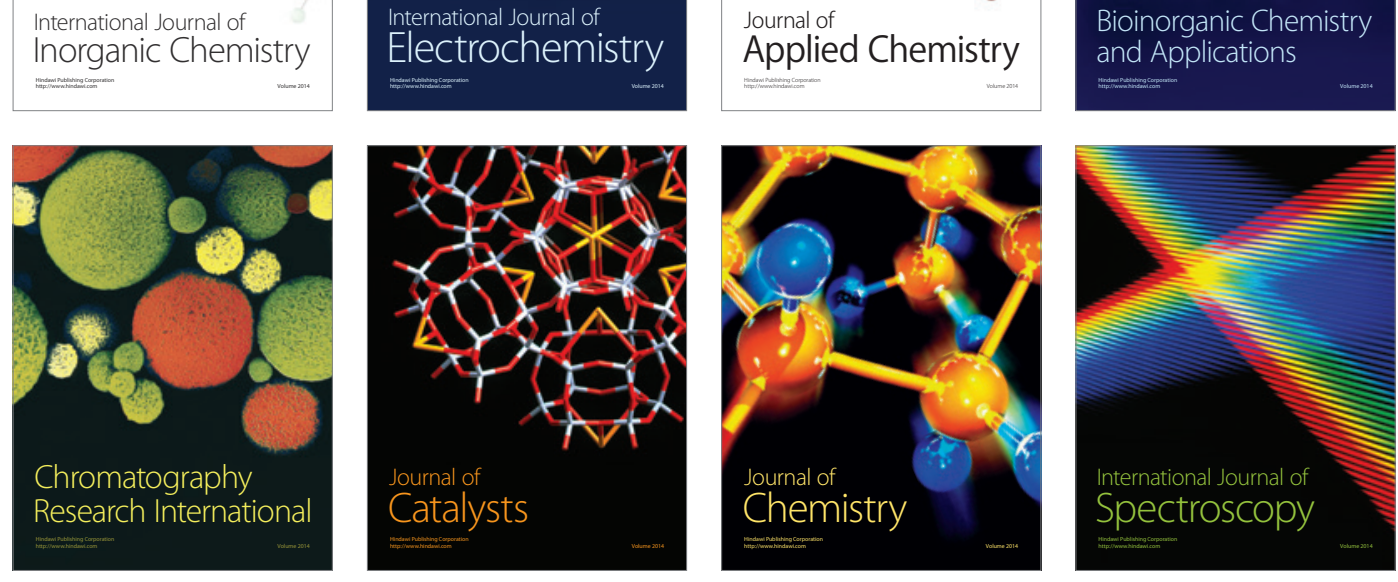